\section{Destruction area disputed}

\section{São Paulo}

Disputes about the true extent of rainforest destruction in Brazil have triggered a minor war in the country's Institute for Space Research (INPE, Instituto de Pesquisas Espaciais).

Brazil's president, José Sarney, claimed on 6 April that INPE figures showed just 5.12 per cent of the area of the 'Legal Amazonia' had been destroyed since colonization began in 1500 . But the true figure may actually be close to 12 per cent according to Vitor Celso de Carvalho, who heads the institute's department of research and applications of remote sensing.

The first estimate was certainly incorrect because it did not relate the deforested area - 251,429 square kilometres - to the total area of forest but to the whole of Amazonia (of which only about 75 per cent is forest). A recalculation taking this into account places deforestation at 6.8 per cent (see Nature 338, 531; 1989).

But that error is just the tip of the iceberg. A second edition of the report includes "ancient deforestation" data too. The area destroyed jumps to 343,975 square kilometres, or 9.3 per cent of the estimated 3.7 million square kilometres of forest. Adding to this the destruction in other kinds of Amazonian vegetation, including the savannah-like 'cerrado', the figure approachs 12 per cent.

Carvalho strongly criticizes the haste with which data was produced for the president's announcement. He says that the short time available to prepare the first report and the lack of reliable data - the team had to use older satellite images for some regions, instead of only 1988 material - "compromised" the work, causing serious damage to the institute's image and credibility.

INPE's first report describes deforestation "up to 1988 ", taken by Sarney in his speech to mean deforestation "since the discovery of Brazil", and "up to 1988". But the institute's director, Márcio Nogueira Barbosa, says that it meant "recent deforestation" only. The 92,546.43 square kilometres of ancient destruction that must now be added is an area three times that of Belgium.

Although Barbosa said earlier that the report was the "most complete" study ever of deforestation in Brazil, anomalies remain. An earlier work by the nowdefunct Brazilian Institute for Forestry Development (IBDF, Instituto Brasileiro de Desenvolvimento Florestal) shows that 8,132 square kilometres of forests were destroyed in the state of Acre by 1987. INPE's reports say the figure is 5,509 square kilometres to 1988 - meaning that Acre has "gained" a forest area of 2,600 square kilometres. Both institutes used
Landsat data.

At the same time that the controversy was raging in INPE's headquarters at São José dos Campos, São Paulo State, Brazil's president was playing host to his colleagues from Amazonian countries in Manaus, in the state of Amazonas. The reunion of the presidents of the Treaty of Amazonian Cooperation ended last Sunday with tirades against foreign intervention in the region's affairs and complaints about external debt payments.

Those present - the presidents of Brazil, Ecuador, Guiana, Surinam, Peru, Venezuela, Colombia and the foreign minister of Bolivia, which is in the middle

\section{London}

THE most comprehensive British study so far of the oral contraceptive pill and the risk of developing breast cancer provides evidence for a substantial causal relationship between prolonged use of the pill and an increased risk of breast cancer in young women. The new study adds to the morass of contradictory evidence on whether or not a link exists, and although not conclusive it swings the balance further than before in favour of a link.

The case-control study involved 755 women diagnosed with breast cancer before the age of 36 , and was carried out by researchers at the Imperial Cancer Research Fund, the Cancer Research Campaign and the University of Oxford. The results, published in The Lancet last week, show an increase in the risk of breast cancer of about 40 per cent after 4-8 years of pill use, and an increase of about 70 per cent after more than 8 years, although pills with lower doses of oestrogen seem to be associated with a lower risk, and progestogen-only pills seem to have a protective effect.

The risk of young women in Britain developing breast cancer is still low: about 1 in 500 . But the new study suggests that one-fifth of the 650 cases a year can be ascribed to pill use. The principal researcher, Clair Chilvers, says women should now aim to use pills with the lowest dose for the shortest possible time.

The Committee on Safety of Medicines (CSM), the government advisory body, is taking a cautious attitude to the findings, pointing out that these risks would be expected to produce a detectable increase in the reported incidence of breast cancer in young women. The fact that no increase has been observed, and the lack of correlation with the risk estimates, cannot be ascribed to under-reporting, it says. But Professor Julian Peto, one of the research of presidential elections - also said that the growing concern of developed countries for the environment should be translated into financial assistance to less well-off countries.

The lack of scientific knowledge of the region was well demonstrated last week when the Brazilian National Foundation of the Indian (FUNAI, Fundação Nacional do Indio) announced its first contact with a tribe of 130 indians in a remote area in the north of the state of Pará, near the Surinam border. Brief contact with the tribe had been made seven years ago by a group of missionaries. In order to make the trip, the FUNAI team had to borrow a helicopter from Petrobras, the country's state-owned oil company.

Ricardo Bonalume Neto

\title{
Increased cancer risk found
}

team, says that registration is unreliable and cannot be used as evidence either way.

In a letter sent to general practitioners last week, the CSM recommends no change in prescribing oral contraceptives, seizing on the fact that the study is concerned mainly with the use of older oral contraceptives which contain higher doses of oestrogen than are the norm today, and that for ovarian and endometrial cancer the pill may be protective. But Chilvers says this attitude is "over-reassuring". She supports the response of the Family Planning Association and the National Association of Family Planning Doctors which both say that women should continue to use their present packet of pills but consult their doctor.

The US Food and Drug Administration reported in January that the evidence for a link between the pill and breast cancer was so conflicting and inconsistent that it was difficult to draw conclusions, and recommended no change in present pill use. A large US study providing evidence against a link has now been challenged by Peto. Carried out for the Cancer and Steroid Hormone Study Group and reported in 1985 in The Lancet, that study concluded that use of the pill had no effect on risk of breast cancer before the age of 45 . After reanalysing the data, Peto comes to the opposite conclusion.

The new British study is now being followed up with a similar one involving women between the ages of 36 and 45 in an attempt to answer the vital question of whether the perceived risk is transient and diminishes at older ages. A study last year by the Royal College of General Practitioners suggested that this was the case, but the researchers say the risk may have been undetectable in previous studies, particularly if there is a latent period between exposure and risk.

Christine McGourty 